\title{
GOVERNANCE FOR SAFETY IN INTER-ORGANIZATIONAL PROJECT NETWORKS
}

\author{
Nadezhda Gotcheva ${ }^{1}$, Kirsi Aaltonen ${ }^{2}$ and Jaakko Kujala ${ }^{2}$ \\ ${ }^{1}$ VTT Technical Research Centre of Finland Ltd, ${ }^{2}$ University of Oulu, Finland
}

\begin{abstract}
Inter-organizational projects are large-scale temporary undertakings, which bring together a multitude of actors who may differ in goals, values, knowledge, experience, culture or business models. A key function of governance in inter-organizational project networks is aligning and coordinating such various autonomous entities to work successfully towards a shared goal. Following a systematic approach for analyzing and categorizing scientific literature in the fields of project management and safety science, this chapter presents six key elements of governance and their mechanisms associated with inter-organizational project networks and synthesizes potential implications on safety. Governance mechanisms influence how work is coordinated and organized in global project networks, and ultimately determine the project actors' commitment and capability to work towards achieving the project goals. This chapter contributes to the vivid conversation in contemporary safety science by connecting discourses of safety and project governance to provide novel insights on inter-organizational factors to be considered when embarking on understanding and enhancing safety in dynamic and uncertain project environments. In conclusion, the chapter provides a fruitful agenda for future research.
\end{abstract}




\subsection{Introduction: Bridging project governance and safety science}

We observe significant rise in the frequency, complexity and magnitude of global projects in areas such as energy production, transportation, aerospace or infrastructure construction. Such projects often pertain potentially high risks to the environment or society, and safety is fundamentally a prerequisite for their existence (Oedewald and Reiman, 2007). These entities bring together a large number of stakeholders such as investors, contractors, subcontractors, local interest groups, government organizations, local communities, political decision makers, and environmental groups (Flyvbjerg et al., 2003). The diversity and dynamics of the stakeholders add to the project complexity and make the management or governance of safety in project networks particularly challenging (Oedewald and Gotcheva, 2015). The concept of governance refers to the notion that project networks cannot be fully controlled by a single organization; governance in project networks is influenced by various factors such as network structure, previous relationships between actors and the potential for future collaboration. Governance differs from project management as it integrates practical knowledge from economics, law, sociology and management to steer interaction processes and structures in inter-organizational networks to nurture further collaboration. Our research complements the traditional approach on managing project networks, which has been emphasizing the role of the focal actor, and has been dominated by the planning and control oriented approach.

The focal finding of project management literature has been that key challenges in complex projects are organizational in character rather than technical. Organizational complexity has been found to have an amplifying effect on escalation of often non-linear consequences that lead to dysfunctional performance (Fleming and Zyglidopoulos, 2008). The need to understand the links between project governance and safety issues became evident in the context of the challenges, experienced in the process of constructing the new nuclear build project Olkiluoto 3 (OL3) in Finland, which is the first European Pressurized Water Reactor (EPR) plant unit in the world. The construction started in 2005 and the unit was supposed to start commercial operation in 2009 yet it is still not operational in 2018. In the beginning of the project, the Radiation and Nuclear Safety Authority in Finland (STUK) identified a number of non-conformances, largely associated with project management (STUK, 2006). This ongoing project has faced many challenges throughout its design and construction phases, 
for example related to communication problems due to long supply chain, unclear roles and responsibilities, shortcomings in quality assurance, related to insufficient understanding of requirements by subcontractors, most of which had limited previous experience in the nuclear industry (STUK, 2011). Oedewald et al. (2011) further investigated the topical issue of managing safety in complex subcontractor networks in the case of OL3 project. The management model of this project was to a large degree a traditional top-down hierarchy (Oedewald and Gotcheva, 2015), which has not been very appropriate for timely identification and dealing with these organizational challenges.

There are many examples of projects in the safety-critical domains that had ended up disastrously, although the specifics of the project context and governance approach has rarely been explicated in accident investigations. For instance, in the offshore industry, the Petrobras P-36 oil-drilling platform sank in 2001 before even being operated due to underlying issues related to poor design of key safetycritical parts, component failure and project management issues evident in focus on cost-cutting and insufficient communication (Wander, 2008). Likewise, the loss of the space shuttles Challenger and Columbia has been largely associated with a performance culture, gradually infused with cost efficiency and focus on meeting production goals and deadlines (Vaughan, 1996; Starbuck and Farjoun, 2005). Pinto (2014) indicated that the "normalization of deviance" (Vaughan, 1996) represents a significant problem in project organizations, and examined the role of organizational learning and corporate governance in identifying and minimizing this negative impact.

On the other hand, well-designed and implemented governance mechanisms are instrumental for ensuring appropriate project planning and delivery, including a good safety performance. Some success stories of complex projects have been, for example, Heathrow Terminal 5 in the UK or the Tampere Lakeside Tunnel project in Finland. Both of these projects have been implemented with an integrated project delivery form, which emphasizes collaboration between project key stakeholders (Brady and Davies, 2010; Hietajärvi et al., 2017). This approach ensured an integrated management system for the overall project network and motivated the key project actors to work towards joint project goals, including strict safety related goals. 
An additional challenge in a project context is that the safety of the project end-product is influenced by decisions made in different project lifecycle stages, particularly during planning, design or construction phases. Different lifecycle stages of a project have distinctive goals and features, which specific safety culture challenges (Gotcheva and Oedewald, 2015). The initiation phase may be negatively affected by unclear definitions or differing opinions regarding the objectives of the project (Ward and Chapman, 1995). There is a need to understand how involvement of diverse and multiple stakeholders, often at different geographical locations, could impact safety, as actors may interpret differently the requirements and related responsibilities (Gotcheva et al., 2016; Gotcheva and Oedewald, 2015). Design has been identified as a significant contributor to recent major accidents, accounting for about fifty percent of accidents and incidents in the aircraft and nuclear industries (Kinnersley and Roelen, 2007). To support safe design, engineers and project managers need to have similar levels of decision-making power to allow for competing goals to be openly discussed (Hayes, 2015). As the project proceeds to the implementation phase, it is challenging to facilitate a shared understanding about safety due to multiple temporary actors. Cagno et al. (2002) highlighted the importance of coordination and good project management in commissioning phase, when major accident safety risks are significantly higher and there are multiple organizational and technical interfaces.

Despite the growing number of inter-organizational projects in diverse safety-critical sectors, safety research has focused primarily on safety management in permanent and single organizational settings, often on operations, with some exceptions (e.g., Oedewald and Gotcheva, 2015). The main theoretical premises in safety science, such as accident causation models or different safety models (safety culture, high-reliability organizations, resilience engineering) have not been based explicitly on studying projects (Le Coze, 2016). Some scholars have recognized inter-organizational aspects as critical yet insufficiently understood in safety research. While delineating future research needs in the field of High Reliability Organizations, Karlene Roberts acknowledged the need to know more about how errors occur at the "interstices", such as "shift changes, relationships between hospital pharmacies and wards, the relationship of organizations with their contractors, the relationships among geographically separate parts of organizations" (Bourrier, 2005: 95). The project context 
Book chapter

Safety Science Research: Evolutions, Challenges and Research Directions, J-Ch. Le Coze (Ed.), Routledge.

provides timely and unique opportunities for advancing our understanding on how safety is ensured in such challenging settings.

\subsection{Governance in project networks}

An inter-organizational project network can be viewed as an intentionally created, temporary dynamic network of organizations that combines the resources, capabilities and knowledge of the participating actors to contribute to a common goal and to fulfil the needs of the owner (Järvensivu and Möller, 2009; Ruuska et al. 2011). Some of the project parties might have little experience and understanding of the specific national and international regulatory requirements, standards and industry practices in general. In this context, ensuring that the safety and quality requirements are adequately understood and fulfilled by every party is a challenging task. Many of the project participants, such as contractors or subcontractors, work also in other non-safety critical industries, so it cannot be expected that they necessary share the same values, knowledge and working methods that support the overall safety goal of the project.

The project governance challenge is to align and coordinate numerous interrelated project roles and activities, characterized by ambiguity of cause-effect relationships and difficulty to understand and control the behavior of the project network actors (Brady \& Davies, 2010; Ahola et al., 2014). In a project context, two distinct streams of governance research can be identified: project governance as external to any specific project, and project governance as internal to a specific project (Ahola et al., 2014). As our research focus is on internal coordination of activities in a project, to avoid confusion, we define governance in project networks as the coordination, adaptation and safeguarding mechanisms that enable multiple organizational actors in project networks to work toward shared goals. We suggest that the concept of governance in project networks is useful for understanding coordination and decision-making in inter-organizational project networks. Governance-related research on safety in inter-organizational projects is relatively limited, and a better understanding is needed of how to design governance systems that take into account safety objectives, especially in situations where a diverse range of stakeholders have somewhat conflicting objectives and differing views about the importance of safety or how it can best be achieved and sustained. It is nevertheless challenging to effectively define safety objectives in terms of major accident hazards for a project 
Book chapter

Safety Science Research: Evolutions, Challenges and Research Directions, J-Ch. Le Coze (Ed.), Routledge.

when potential issues may be manifested years into the future, long after the project organization has been disbanded.

The organizational structures of complex projects are often characterized as hierarchical contract organizations (Morris and Hough, 1987). The purpose of a project's contract organization is to create a cooperative system, and this is accomplished by achieving common objectives by properly incentivizing the contractors with contract pricing terms. Ruuska et al. (2011) analyzed supply networks of Olkiluoto 3 and Flamanville 3 nuclear power plant projects, and they support Miller and Lessard (2000) by suggesting that there should be a shift from viewing multi-firm projects as hierarchical contract organizations to viewing them as supply networks characterized by a complex and networked relationships. Furthermore, Ruuska et al. (ibid.) suggests that there should be a shift in the emphasis of the predominant modes of governance, market and hierarchy towards novel governance approaches that emphasize network-level mechanisms such as self-regulation within the project.

Governance in project networks can be based on a shared effort between the participants, or it can be exercised by a single network member (a lead organization) or by an external network administrator organization (Provan and Kenis, 2008). Despite recent efforts of taking a broader look at governance in project networks (Ahola et al., 2014; Kujala et al., 2015) and network form of governance in general (Jones et al., 1997), going beyond single-hub-firm-driven approach is still a less discussed perspective in the previous literatures on project networks and strategic business networks.

\subsection{Key elements of governance in inter-organizational project networks}

This framework synthesizes key elements of governance in inter-organizational project networks, and is based on integration of two systematic literature reviews, which followed a structured approach for analyzing and categorizing literature in the fields of project management and safety science. Based on the analysis of project management literature we identified six key elements of governance in inter-organizational project networks and their corresponding mechanisms (Kujala et al., 2016). These key elements were used for the subsequent systematic literature review, which focused on verifying if these dimensions are found in the safety literature (Starck, 2016). These reviews and 
Book chapter

Safety Science Research: Evolutions, Challenges and Research Directions, J-Ch. Le Coze (Ed.), Routledge.

identified taxonomy of governance dimensions and mechanisms, laid the foundation of the governance framework in inter-organizational project networks (Figure 1).

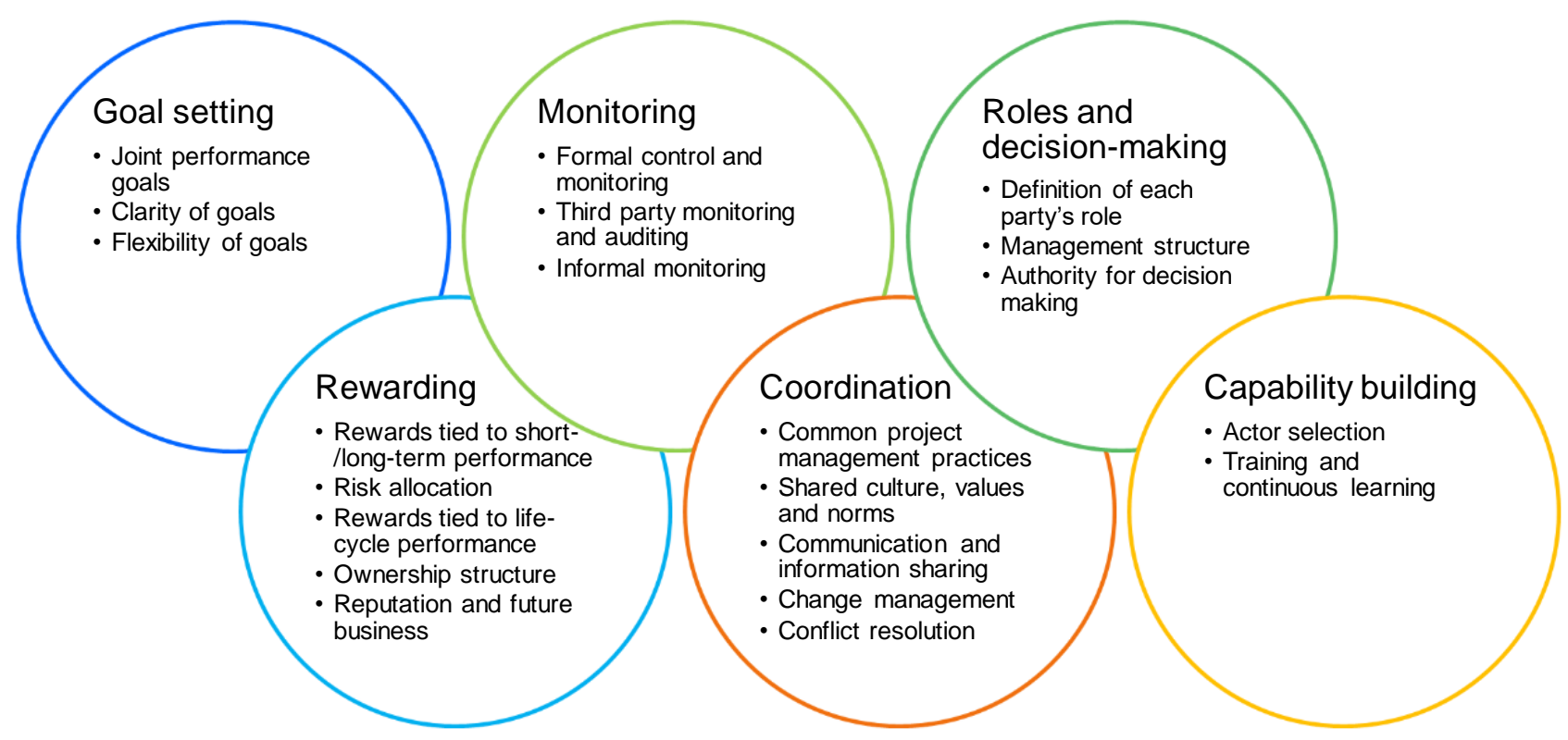

Figure 1: Key elements and mechanisms associated with governance in inter-organizational project networks.

Governance mechanisms influence how work is coordinated and organized in project networks, and ultimately determine the organizations' commitment and capability to work towards achieving project goals. Commitment and capability to understand safety and hazards and to act in a manner that ensures safety in daily activities are seen as critical for a good safety performance (Reiman and Pietikäinen, 2010; Reiman et al., 2012). Governance mechanisms may influence commitment to safety, for example by enabling project actors to jointly create project safety related goals, having effective monitoring practices to ensure that these goals are achieved and providing reward for meeting the goals. Similarly project governance mechanisms such as effective communication and information sharing, or selection of actors based on their competence influence the ability of actors to meet project safety goals. 
Book chapter

Safety Science Research: Evolutions, Challenges and Research Directions, J-Ch. Le Coze (Ed.), Routledge.

\subsubsection{Goal setting}

Goal setting seeks to create shared performance goals for the project that are properly understood by all project actors. In general, project goals include both short-term goals focusing on project implementation process and long-term goals related to use and benefits gain from the end-result (Nisar, 2013). The impact of joint performance goals on safety is a relevant issue, especially in relation to the different positions and roles of stakeholders. In safety literature, performance indicators for high-hazard industries have been studied; in particular, the need to define leading indicators, that is, measures that intend to predict patterns or trends of events (Hopkins, 2009; Reiman and Pietikäinen, 2012). In safety-critical projects, potential goal conflicts between schedule, cost, scope and safety can influence the capability of project actors to understand the links between short-term actions and long-term consequences.

The existing research acknowledges the importance of early involvement of all project actors in the process of establishing joint goals in an inter-organizational project network (Guo et al., 2014; Davies et al., 2014). This is needed to ensure optimal understanding of needs and proper interpretation of safety requirements despite differences in actors' experiences and backgrounds. Setting shared goals with regard to safety, for example how safety culture is measured and continuously improved, includes the establishment of shared principles and expectations among the project actors. As complex projects always involve changes that cannot be anticipated, project goals and the contracting process must also be sufficiently flexible to respond to unforeseen risks and opportunities (Davies et al. 2014). Additionally, continuous improvement of safety calls for flexibility of goals as the ways in which safety can be achieved is context dependent and there are multiple ways it can be achieved and maintained in different organizations.

\subsubsection{Rewarding}

Rewarding refers to aligning actors' goals with project goals by means of incentives. These may include monetary incentives linked to joint performance goals (Davies et al. 2014), conditional future payments and work prompting a life-cycle approach (van den Hurk and Verhoest 2015; Nisar 2013), as well as reputational scoring systems (Guo et al. 2014). The effectiveness and challenges of using 
Book chapter

Safety Science Research: Evolutions, Challenges and Research Directions, J-Ch. Le Coze (Ed.), Routledge.

bonuses and other rewards has been discussed in safety literature as well. For instance, Maslen and Hopkins (2014) reminded that in recent offshore industry disasters the incentives were dysfunctional and worked against process safety. Drawing on the literature on human motivation and incentives, they studied how senior managers are motivated by incentives in their daily decisions in hazardous industries. The main insight from this work is that incentives do influence priorities and behaviours because they tap basic human needs, such as the need for approval, and the need to be recognized as making a valuable contribution. The authors conclude that safety, in terms of major accident prevention, should be incentivized at least in the same way as financial and business performance. Incentives need to be designed carefully though.

McDermott et al. (2017) investigated senior executives long-term incentive plans and safety objectives in the construction sector in Australia, and identified that these plans were exclusively associated with financial indicators; that is, senior executives were not incentivized to align their long-term decision-making with long-term safety objectives. Furthermore, using financial incentives to boost productivity in safety-critical industries may trigger unsafe acts (Sawacha et al., 1999). For instance, collective bonus schemes were found to inhibit reporting of safety concerns for fear of losing one's bonus (Collinson, 1999). Incentives may discourage some actors to report safety deficiencies, if they believe it may cause immediate additional costs or may negatively affect future business opportunities. The incentives such as determination of who carries additional costs related to safety related risks may be used to discourage such behavior. For example, in alliance contracts risks are shared by all project participants. The determination of who carries the cost of risk is especially relevant if suppliers' risk bearing capacity is low and as a result they are more likely to not report errors (Osmundsen et al., 2010). In that sense, creating a sense of ownership through contractual means among participating organizations is also important (Guo et al., 2014).

\subsubsection{Monitoring}

Monitoring seeks to ensure that all actors behave as expected and it enables the use of performancebased incentives. To be useful, project milestones and performance targets must not only be realistic 
Book chapter

Safety Science Research: Evolutions, Challenges and Research Directions, J-Ch. Le Coze (Ed.), Routledge.

but must also be monitored (Nisar, 2013). Abednego and Ogunlana (2006) highlighted the importance of continuous project control and monitoring in pursuit of common goals and to satisfy all interests. In safety-critical organizations, monitoring includes both system activities and boundaries and potential sources of risk in the system (Reiman et al., 2015). Recent safety literature on monitoring and audit also warns of the perils of an over-focus on compliance, particularly in multi-tier contracting chains (e.g. McDermott and Hayes, 2018). Governance mechanisms could be structured to provide balance in this regard; managers must not only attend in general to the behaviors and interactions that characterize a group or an organization, such as violations of rules and procedures, but must also organize monitoring of technology and physical processes that are critical for system safety. Osmundsen et al. (2008) noticed that there is an increased use of key performance indicators and incentive schemes in the Norwegian petroleum industry and observed that there is lack of effective incentives for safety since the main emphasis is on more tangible performance dimensions that are easier to monitor. Hence, it is challenging to create good performance indicators for monitoring safety and use them for incentives, because safety includes a lot of "soft" aspects that are difficult to measure.

As acknowledged by Weick (1998), monitoring system activities and boundaries depends on organizational decisions about what information is relevant for safety (and what can be ignored). In the safety literature, Burns (2006) emphasized the importance of proactive monitoring in the petrochemical industry, as done in three stages: deviation detection, problem prediction by determining what effect the deviation will have in the future, and taking compensatory action. Based on self-regulation framework, Griffin and $\mathrm{Hu}$ (2013) indicated that monitoring done by leaders in a learning supporting environment could improve safety: the emphasis is on leaders awareness of unsafe behavior and errors, and their ability to encourage employees to learn and challenge the current safety system.

\subsubsection{Coordination}

Coordination is required to align the behavior of each actor so that they can effectively work together. Formally, project contracts and project plans define processes for implementing project work, and 
Book chapter

Safety Science Research: Evolutions, Challenges and Research Directions, J-Ch. Le Coze (Ed.), Routledge.

specify tools and practices for carrying out project work. Informal types of coordination such as shared values and behavioral norms can have a significant impact on how project actors work together to ensure safety. These behavioral norms may also be included as part of the contract document, which may include values, norms and expectations for a project (Caldwell et al., 2009). The challenge posed by these informal coordination mechanisms is that cultural and organizational boundaries can hinder the creation of shared behavioral norms for a project (Bresnen and Marshall, 2000; Dossick and Neff, 2011).

Reason and Hobbs (2003: 105) indicated that "a breakdown in coordination is one of the most common circumstances leading to an incident. In many cases, coordination breaks down when people make unspoken assumptions about a job, without actually communicating with each other to confirm the situation." Another important aspect of coordination is to ensure that all parties have the information they need to complete their work in collaboration with other project parties. Information sharing is ensured by practices such as regular meetings or co-location of project teams. Brady and Davies (2014) described a single model environment, which ensured that all parties could access a central repository for all digital data, as one of the key success factors in the Heathrow T5 project.

\subsubsection{Roles and decision making}

Roles and decision-making refer to giving actors the necessary information to understand the effect of decisions on overall performance, enabling them to make appropriate decisions. Roles of different project parties in safety-critical industries are oftentimes mandated by law. For example, the licensee in a nuclear industry project is ultimately responsible for safety. In case of turnkey delivery nuclear industry projects, the plant supplier is usually responsible for the design, construction, installation and commissioning of the plant. Although the formal roles and responsibilities of each party are defined contractually ( $\mathrm{Lu}$ et al., 2015), effective governance incorporates suitable project management structures and decentralized decision-making principles (Abednego and Ogunlana, 2006; Nisar, 2013; Pitsis et al., 2014). For example, creating a leadership team that is legally and spatially separate from the parent organizations may help in coping with unknowable future events and avoiding disputes (Sanderson, 2012), while clearly defined management team can support and assume responsibility for daily execution of the project (van Marrewijk and Smits, 2015). 
Book chapter

Safety Science Research: Evolutions, Challenges and Research Directions, J-Ch. Le Coze (Ed.), Routledge.

Effective governance requires also that decision-making power is appropriately distributed between actors (Eriksson, 2010; Nisar, 2013). According to Ruuska et al. (2011), companies' responsibilities should be allocated on the basis of their competence, capabilities and risk-bearing capacity, while Abednego and Ogunlana (2006) highlighted the importance of equality and active participation in making the "right decisions at the right time." In projects emphasizing relational governance, democratic decision-making mechanisms are needed to build trust and confidence in relationships (Nisar, 2013). As implied by polycentric governance (Woods and Branlat, 2011), on the one hand project network actors have sufficient autonomy and decision-making power within their domain of competence, on the other hand they also have responsibilities for achieving the shared project goals. In terms of safety performance, polycentric governance approach assigns an active role even for small subcontractors at the periphery of the project network. In this process, knowledge sharing also involves sharing of cultural information about safety (Oedewald and Gotcheva, 2015).

\subsubsection{Capability building}

Capability building ensures that project actors have adequate abilities and potential to meet performance expectations. The aim is to ensure that appropriate skills and expertise are identified and tied to the project at an early stage, and that sufficient attention is devoted to resourcing the project team (Nisar, 2013). The use of suitable competitive tendering processes and selection criteria play an important role in capability building (van den Hurk and Verhoest, 2015). Beyond procurement, systematic training and continuous learning with regard to safety and its management during projects, and from project to project to get operational lessons into the project process, can also enhance capability (Davies et al., 2014; Guo et al., 2014; Ruuska et al., 2011). Practical means to develop capabilities in a temporary project context include, for example, retrospectives, systematic lessons learned sessions, joint workshops, joint trainings and education, capability and competence mapping and related staffing policy, building of common ground and collective capabilities through agreeing on joint processes, reviews, etc.

From a safety perspective, capability building for continuous improvement of safety is also highly relevant. This can take various forms such as preventive actions, corrective actions and reviews. 
Combining project and safety research domains points also to the issue of learning in such dynamic environments. As indicated by Le Coze (2013) is his reflection about learning from accidents, interests between different actors may lead to difficulties in reporting near misses or incidents. Capability building in safety-critical domains also entails increased mindfulness to make sense of situational requirements and to heighten awareness of when it is appropriate to cross boundaries (e.g., to receive information or use available resources) or to adjust or interpret rules according to situational requirements (Reiman et al., 2015). Actors involved in safety-critical projects need sufficient understanding and knowledge regarding the nature of hazards, possible new hazards, need for strict rules and fulfilling the requirements (Oedewald and Gotcheva, 2015). Good relationships and trust are essential for developing situational self-organizing or adjustment capability in interorganizational project networks, again requiring effective governance to steer positive interactions between project actors.

\subsection{Concluding remarks and future research directions}

This chapter advances the understanding of what constitutes governance for safety in the context of inter-organizational project networks, comprising multiple autonomous organizations, which interests need to be aligned to achieve a joint system-level goal. Our focus is on project network governance elements to coordinate, adapt and safeguard work between autonomous project actors. Governance does not stay the same throughout the project - it can be seen as "impermanent" as it needs to be continuously tailored and adapted. The notion of impermanence (Weick, 2001) is seen as inherent in organizations, insofar as the process of organizing is ongoing and adaptive rather than stable and fixed; continuously occurring "between smoke and crystal" (Atlan, 1979). While 'smoke' relates to unpredictability in terms of variety and complexity, 'crystal' refers to stability in terms of repetition and habit in organizations (Taylor and Van Every, 2000). The underlying assumption of the governance in project networks framework is that project actors collectively act as "system architects" and create the governance structure in the project network through their decision-making processes, capabilities, negotiations and interaction. This approach complements the view that emphasizes the role of the "strong owner" (Sallinen et al., 2008; Winch and Leiringer, 2016) in setting the tone and culture for the entire project network. 
To bridge the gap between project governance and safety science, in this chapter we described the key elements associated with governance in safety-critical inter-organizational projects networks. Further conceptual development is needed to inform empirical research and build detailed propositions on actual decision making and formation processes of project governance in interorganizational settings (van Marrewijk and Smits, 2015). Our research also highlights the need for a deeper understanding of how structural and other characteristics of the project network affect safety performance culture and governance for safety. A single project network may accommodate diverse governance regimes, raising interesting questions about how this may affect safety at the project network level, and how the different governance elements should be tailored to support safety across the boundaries of the different parts of a project network.

The variety of connections in complex project networks has been underestimated - for instance, vertical and horizontal interactions co-exist. The polycentric governance approach is central for complex nuclear projects to acknowledge actors on the periphery of the network (e.g., small subcontractor companies) as active partners in developing a shared project culture (Ruuska et al., 2011). From that perspective, horizontal interactions between project partners could be seen as equal in importance to bilateral hierarchical connections (Oedewald and Gotcheva, 2015). It is therefore important to understand how governance elements could be utilized to constructively affect the ability of the project owner/licensee and other project actors to ensure that the project's safety goals are met during the whole project lifecycle.

The governance for safety framework developed here also invites a contingency perspective on governance of safety-critical projects, which requires tailoring the governance elements to project's specific context and characteristics. Future research could seek to identify the contingency factors most relevant to safety. The role of temporality is also interesting in terms of governing safety in different points of time and phases of the project since safety is continuously co-created by project actors' daily decisions and activities.

Inter-organizational project networks within contemporary safety-critical domains are typically global and multicultural, involving a large number of participants from different occupational and institutional backgrounds. Future research should explore the implications of this diversity for safety 
Book chapter

Safety Science Research: Evolutions, Challenges and Research Directions, J-Ch. Le Coze (Ed.), Routledge.

performance and shared understandings of safety. Given that governance mechanisms differ across companies in the project network as well as across national backgrounds, it becomes increasingly important to understand the role of governance in safety-critical projects such as nuclear industry new builds or decommissioning projects. Another potentially fruitful area for further research concerns the role of regulation, as local regulations significantly influence the development and implementation of both governance systems and safety management systems.

\section{Acknowledgements}

This chapter extends on previous research carried out by Kujala et al. (2016), presented at the European Academy of Management (EURAM) conference, 1-4 June 2016, Paris, France, and Starck (2016). The work summarized in this chapter was conducted as a part of research project Management Principles and Safety Culture in Complex Projects (MAPS). The authors wish to acknowledge the funding provided by SAFIR2018, The Finnish Research Programme on Nuclear Power Plant Safety (2015-2018), University of Oulu and VTT Technical Research Centre of Finland. 
Book chapter

Safety Science Research: Evolutions, Challenges and Research Directions, J-Ch. Le Coze (Ed.), Routledge.

\section{References}

Abednego, M.P., Ogunlana, S.O., 2006. Good project governance for proper risk allocation in public-private partnerships in Indonesia. International Journal of Project Management, 24, 622-634.

Ahola, T., Ruuska, I., Artto, K., Kujala, J., 2014. What is project governance and what are its origins? International Journal of Project Management, 32, 1321-1332.

Atlan, H. 1979. Entre le cristal et la fume [Between crystal and smoke]. Paris: Editions du Seuil.

Bourrier, M., 2005. An interview with Karlene Roberts, European Management Journal, 23(1), pp. 93-97.

Brady, T., Davies, A. 2010. Learning to Deliver a Mega-project: The Case of Heathrow Terminal 5 In: Caldwell, Nigel and Howard, Mickey, eds. Procuring Complex Performance: Studies of Innovation in Product-Service Management. Routledge, New York, USA, pp. 174-198.

Brady, T., Davies, A., 2014. Managing structural and dynamic complexity: A tale of two projects. Project Management Journal, 45, 21-38.

Bresnen M., Marshall N., 2000. Motivation, commitment and the use of incentives in partnerships and alliances. Construction Management and Economics, 18, 587-598.

Burns, C. M., 2006. Towards proactive monitoring in the petrochemical industry. Safety Science, 44, 27-36.

Cagno, E., Caron, F., M. Mancini, 2002. Risk analysis in plant commissioning: the Multilevel Hazop. Reliability Engineering \& System Safety 77 (3), pp. 309-323.

Caldwell, N., Roehrich, J., Davies, A., 2009. Procuring complex performance in construction: London Heathrow Terminal 5 and a Private Finance Initiative hospital. Journal of Purchasing and Supply Management, 15(3), 178-186.

Collinson, D.L., 1999. Surviving the rigs: Safety and surveillance on North Sea oil installations. Organization Studies, 20(4), 579-600.

Davies, A., Macaulay, S., Debarro, T., Thurston, M., 2014. Making innovation happen in a megaproject: London's crossrail suburban railway system. Project Management Journal, 45(6), 25-37.

Dossick, C.S., Neff, G., 2011. Messy talk and clean technology: Communication, problem-solving and collaboration using building information modelling. The Engineering Project Organization Journal, 1(2), 83-93.

Eriksson, P.E., 2010. Improving construction supply chain collaboration and performance: A lean construction pilot project. Supply Chain Management: An International Journal, 15(5), 394-403. 
Book chapter

Safety Science Research: Evolutions, Challenges and Research Directions, J-Ch. Le Coze (Ed.), Routledge.

Fleming, P., Zyglidopoulos, S. 2008. The escalation of deception in organizations, Journal of Business Ethics, 81:837850.

Flyvbjerg, B., Bruzelius, N. \& Rothengatter, W. 2003. Megaprojects and Risk: An Anatomy of Ambition. Cambridge.

Gotcheva, N., Oedewald, P. 2015. SafePhase: Safety culture challenges in design, construction, installation and commissioning phases of large nuclear power projects, February, 2015:10, ISSN 2000-0456, Swedish Radiation Safety Authority (SSM).

Gotcheva, N., Oedewald, P., Wahlström, M., Macchi, L, Osvander, A.-L., Alm, H., 2016. Cultural features of design and shared learning for safety: A Nordic nuclear industry perspective. Safety Science, Special Issue: Learn and Train for Safety, 81, 90-98.

Griffin, M. A., Hu, X., 2013. How leaders differentially motivate safety compliance and safety participation: The role of monitoring, inspiring, and learning. Safety Science, 60, 196-202.

Guo, F., Chang-Richards, Y., Wilkinson, S., Li, T., 2014. Effects of project governance structures on the management of risks in major infrastructure projects: A comparative analysis. International Journal of Project Management, 32, 815-826.

Hayes, J., 2015. Investigating design office dynamics that support safe design, Safety Science, 78, 25-34.

Hietajärvi, A-M., Aaltonen, K., Haapasalo, H., 2017. Managing integration in infrastructure alliance projects: Dynamics of integration mechanisms. International Journal of Managing Projects in Business, 10(1), 5-31.

Hopkins, A. 2009. Thinking about process safety indicators. Safety Science, 47, 460-465.

Järvensivu, T., K. Möller. 2009. Metatheory of network management: A contingency perspective. Industrial Marketing Management, 38(6), 654-661.

Jones, C., Hesterly, W., Borgatti, S., 1997. A general theory of network governance: Exchange conditions and social mechanisms. The Academy of Management Review, 22(4), 911-945.

Kinnersley, S. Roelen, S. 2007. The contribution of design to accidents. Safety Science, 45(1-2), 31-60.

Kujala, J., Aaltonen, K., Gotcheva, N. and Pekuri, A. 2016. Key dimensions of project network governance and implications for safety in nuclear industry projects, European Academy of Management (EURAM), 1-4 June 2016, Paris, France.

Le Coze, J. C., 2013. What have we learned about learning from accidents? Post-disasters reflections, Safety Science 51(1), 441-453. 
Book chapter

Safety Science Research: Evolutions, Challenges and Research Directions, J-Ch. Le Coze (Ed.), Routledge.

Le Coze, J. C., 2016. Vive la diversité! High Reliability Organisation (HRO) and Resilience Engineering (RE), Safety Science.

Lu, P., Guo, S., Qian, L., He, P., Xu, X. 2015., The effectiveness of contractual and relational governances in construction projects in China. International Journal of Project Management, 33, 212-222.

Maslen, S., Hopkins, A. 2014. Do incentives work? A qualitative study of managers' motivations in hazardous industries. Safety Science, 70, 419-428.

McDermott, V., J. Hayes. 2018. Risk shifting and disorganization in multi-tier contracting chains: The implications for public safety, Safety Science, July, 106, 263-272.

McDermott, V., Zhang, R.P., Hopkins, A., J. Hayes. 2017. Constructing safety: investigating senior executive long-term incentive plans and safety objectives in the construction sector, Construction Management and Economics, 36(5), 276290.

Miller, R., Lessard, D., 2000. The Strategic Management of Large Engineering Projects: Shaping Institutions, Risks, and Governance. Cambridge, MA: MIT Press.

Morris, P.W.G., Hough, G.H, 1987. The Anatomy of Major Projects: A Study of the Reality of Project Management, John Wiley and Sons, UK.

Nisar, T.M., 2013. Implementation constraints in social enterprise and community Public Private Partnerships. International Journal of Project Management, 31, 638-651.

Oedewald, P., Gotcheva, N., 2015. Safety culture and subcontractor network governance in a complex safety critical project. Reliability Engineering and System Safety, 141 (September), 106-114.

Oedewald, P., Reiman, T. 2007. Special characteristics of safety critical organizations: Work psychological perspective, Espoo, VTT Publications 633.

Oedewald, P., Gotcheva, N., Reiman, T., Pietikäinen, E., Macchi, L. 2011. Managing safety in subcontractor networks: The case of Olkiluoto 3 nuclear power plant construction project. 4th Resilience Engineering International Symposium, Sophia-Antipolis, France, 8-10 June.

Oedewald, P., Gotcheva, N., Viitanen, K., Wahlström, M. 2015. Developing safety culture and organizational resilience in nuclear industry throughout the different lifecycle phases, "Managing safety culture throughout the lifecycle of nuclear plants" (MANSCU), 2011-2014, Final project report. VTT Technology. 
Book chapter

Safety Science Research: Evolutions, Challenges and Research Directions, J-Ch. Le Coze (Ed.), Routledge.

Osmundsen, P., Aven, T. and Vinnem, J. E. 2008. Safety, economic incentives and insurance in the Norwegian petroleum industry. Reliability Engineering and System Safety, 93 (1), pp. 137-143.

Osmundsen, P., Aven, T. \& Tomasgard, A., 2010. On incentives for assurance of petroleum supply. Reliability Engineering and System Safety, 95(2), 143-148.

Pinto, J., 2014. Project management, governance, and the normalization of deviance, International Journal of Project Management, 32(3), 376-387.

Pitsis, T.S., Sankaran, S., Gudergan, S., Clegg, S.R., 2014. Governing projects under complexity: Theory and practice in project management. International Journal of Project Management, 32, 1285-1290.

Provan, K., P. Kenis. 2008. Modes of Network Governance: Structure, Management, and Effectiveness, Journal of Public Administration Research and Theory, 18(2), 229-252.

Reason, J., Hobbs, A. 2003. Managing Maintenance Error. A Practical Guide. Hampshire: Ashgate.

Reiman, T., Pietikainen, E. 2012. Leading indicators of system safety - Monitoring and driving the organizational safety potential. Safety Science, 50(10), 1993-2000.

Reiman, T., Rollenhagen, C., Pietikäinen, E., Heikkilä, J., 2015. Principles of adaptive management in complex safetycritical organizations. Safety Science, 71, Part B, 80-92.

Ruuska, I., Ahola, T., Artto, K., Locatelli, G., Mancini, M., 2011. A new governance approach for multi-firm projects: Lessons from Olkiluoto 3 and Flamanville 3 nuclear power plant projects. International Journal of Project Management, $29,647-660$.

Sallinen L., Ruuska I., Ahola T., 2008. How governmental stakeholders influence large projects: the case of nuclear power plant projects", International Journal of Managing Projects in Business, 6(1), 51-68.

Sanderson, J., 2012. Risk, uncertainty and governance in megaprojects: A critical discussion of alternative explanations. International Journal of Project Management, 30, 432-443.

Sawacha, E., Naoum, S., Fong, D., 1999. Factors affecting safety performance on construction sites. International Journal of Project Management, 17(5), 309-315.

Starbuck,W. H., M. Farjoun (Eds.) 2005. Organization at the Limit: Lessons from the Columbia Disaster. Malden, MA: Blackwell Publishing. 
Book chapter

Safety Science Research: Evolutions, Challenges and Research Directions, J-Ch. Le Coze (Ed.), Routledge.

Starck, M. 2016. Key dimensions of project governance and their relation to nuclear safety- An explorative study of nuclear industry projects, Master's thesis, Department of Management and Organization, Hanken School of Economics, Helsinki.

STUK, 2006. Management of safety requirements in subcontracting during the Olkiluoto 3 nuclear power plant construction phase. Investigation Report 1/06, Nuclear reactor regulation translation, 1.9.2006.

STUK, 2011. Investigation of the procurement and supply of the emergency diesel generators (EDG) and related auxiliary systems and equipment for the Olkiluoto 3 nuclear power plant unit. The Radiation and Nuclear Safety Authority.

Taylor, J. R.,Van Every, E. J., 2000. The emergent organization: Communication as its site and surface. Mahwah, NJ: Erlbaum.

Van den Hurk, M., Verhoest, K., 2015. The governance of public-private partnerships in sports infrastructure: Interfering complexities in Belgium. International Journal of Project Management, 33, 201-211.

van Marrewijk, A. and Smits, K. 2016. Cultural practices of governance in the Panama Canal Expansion Megaproject. International Journal of Project Management, 34(3), 533-544.

Vaughan, D. 1996. The Challenger Launch Decision. The University of Chicago Press, Chicago.

Wander, S., 2008. System Failure Case Studies: That Sinking Feeling, NASA Safety Center, 2(8), 1-4.

Ward, S.C., Chapman, C.B., 1995. Risk-management perspective on the project life cycle, International Journal of Project Management, 13(3), 145-149.

Weick. K.E. 1998. Foresights of failure: an appreciation of Barry Turner. Journal of Contingencies and Crisis Management, 6, 72-75.

Weick, K. E., 2001. Making Sense of the Organization: The Impermanent Organization. Oxford: Blackwell Publishing.

Winch, G. and Leiringer, R., 2016. Owner project capabilities for infrastructure development: A review and development of the "strong owner" concept. International Journal of Project Management, 34(2), 271-281.

Woods, D., Branlat, M. 2011. How human adaptive systems balance fundamental trade-offs: Implications for polycentric governance architectures. $4^{\text {th }}$ Resilience Engineering Symposium, Sophia-Antipolis, France, 8-10 June. 